\title{
ESTIMATION OF WILLINGNESS TO PAY FOR WASTEWATER TREATMENT SERVICE IMPROVEMENT IN MALAYSIA
}

\author{
Chandramalar Munusami* \\ Universiti Kebangsaan Malaysia
}

Jamal Othman

Universiti Kebangsaan Malaysia

Shaharuddin Mohamad Ismail

Universiti Kebangsaan Malaysia

Chamhuri Siwar

Universiti Kebangsaan Malaysia

\begin{abstract}
As populations increase by leaps and bounds, it places more pressure on the environment and threatening sources of fresh water supplies, it was recognized that the problem of wastewater needed proper management in Malaysia. This study is undertaken to assist the relevant governmental bodies and service providers to identify an improved wastewater management strategy from the consumer perspectives. This paper applies a structural equation model (SEM) to analyze willingness to pay for wastewater treatment services improvement, based on a crosssectional dataset of 600 randomly selected urban households in Shah Alam, Bangi, Kajang and Banting areas. The study applies focus group discussions, variables such as environmental awareness (green product), household attitude (water consumption), perceptions (sewerage and wastewater treatment services) and service improvements (willingness to pay) were identified. The main results indicate that environmental awareness, household attitude and perceptions on sewerage services have a positive influence on the service improvements. Households attitude on sewerage and wastewater treatment services are the main determinants of willingness to pay and strongly interact (87 percent) with sewerage service improvement. In conclusion, the methodology applied to measure the household attitudes provides valuable information to policy makers regarding main factors that improve wastewater treatment service efficiency.
\end{abstract}

Keywords: Wastewater; Structural Equation Model; Willingness-To-Pay.

\section{INTRODUCTION}

Malaysia's population is increasing rapidly and will reach 32 million in 2020 (Lo \& Leow, 2014). As population increases, so does the production of wastewater and the number of

\footnotetext{
"Corresponding author: Chandramalar Munusami, Institute for Environment and Development, National University of Malaysia (UKM), 43600 UKM Bangi, Selangor, Malaysia. Telephone: 603-89243762. Email: chandramalar_cm@yahoo.com
} 
number of people vulnerable to the impacts of severe wastewater pollution. Household wastewater treatment services have become a major challenge for Malaysia, due to the fragmented management plans as well as increasing awareness on environmental quality and better education on public health. Wastewater from household may contain harmful dissolved or suspended matter and unregulated discharge of wastewater undermines biological diversity, natural resilience and the capacity of the ecology to provide fundamental ecosystem services. The Malaysian government is currently deliberating on improving the quality of household wastewater treatment services. However, any improvements would likely entail higher sewerage charges to households. This study estimates environmental awareness, household attitude and perceptions of household in aspect of water use, wastewater treatment and services in Malaysia as well as their willingness to pay to obtain such improvements.

Indah Water Konsortium, is Malaysia's national sewerage company which has been entrusted with the task of developing and maintaining a modern and efficient sewerage system for all Malaysians. A modern and efficient sewerage system is vital for the country so as to ensure that wastewater is treated before being discharged into our rivers. This will help preserve the country's waste resources, protect public health and provide a cleaner and safer environment. Therefore, this study focused on willingness to pay for wastewater treatment service improvement in Malaysia especially in Selangor due to high population rate.

The enforcement of the Environmental Quality Act (EQA) in 1974 shows that the water quality of Malaysian inland water especially rivers is following a deteriorating trend. The rivers are mainly polluted due to the point and nonpoint pollution sources. Point sources are monitored and controlled by the Department of Environment (DOE), whereas a significant amount of pollutants is contributed by both untreated wastewater and storm runoff. Therefore some bold steps needed for the effective control of non-point source pollution and untreated wastewater discharge, which play significant roles on the status of the rivers. However, Mamun and Zainuddin (2013) stated that the new regulation for sewage and industrial effluent limits set allowable NH3-N concentration quite high $(5 \mathrm{mg} / \mathrm{L})$, which may result in low Water Quality Index (WQI) values for the river water. The water environment is a dynamic system. Periodical review of the monitoring requirements, detecting emerging pollutants in sewage, effluent and runoff, and proper revision of water quality standards are essential for the management of sustainable water resources, in the country.

Furthermore, the standard economic models assume that producers conclude economic decisions based on profit maximization (Tang et al. 2013). One disadvantage of these models is that they neglect psychological and sociological factors, which also affect economic behavior. Specifically, Folmer (2009) argues that human behavior, including economic behavior, is strongly influenced by awareness, perceptions, expectations and habits. Weck-Hannemann and Frey (1995) argue that intrinsic motivation and internal sanctions promote environmentally-friendly behavior. Intrinsic motivation and internal sanctions in their turn strongly depend on environmental awareness and perception, which perception, which thus determine attitudes that affect future behaviors (Bayard and Jolly, 2007). Hence, to understand household demand for water consumptions and 
wastewater treatment services, insight into their awareness, attitudes and perception of the problem is a prerequisite for the development of adequate and effective policy handles. Awareness, attitudes and perception selected as reflective because they are psychological constructs that determine the indicators such that a change of perception, attitudes or awareness leads to changes in household's willingness to pay for sewerage service improvement and also households' responses to the measurement questions.

\section{METHOD OF THE STUDY}

The study area centers on developed district (Shah Alam), moderately developed district (Bangi and Kajang) and less developed district (Banting) in the state of Selangor Darul Ehsan in Peninsular Malaysia. Furthermore, this study focused on households that connected to the central sewerage system particularly paid MYR8.00 per household per month for sewerage services. The survey took 1 month to complete with employment of 6 enumerators who picked respondents randomly around the study area within the vicinities of developed district (165 respondents), moderately developed district (380 respondents) and less developed district (55 respondents). The sample size was considered comfortable for use in surveys on environmental valuation studies in Malaysia, considering the high survey cost and budget constraints. Of the 3 type of districts, Banting is the smallest; thus, the samples allocated to Banting were smaller than those to the other 2 districts.

Prior to conducting the survey, the enumerators attended trainings conducted by the researchers. They were briefed on the idea of economic valuation, the types of Wastewater Treatment (WWT) technologies, the background of the study and participated in role-play exercises to expose the enumerators to ways of obtaining cooperation from the respondents. Enumerators were informed of possible biases (like strategic, information and starting-point biases) during interviews and ways to minimize them.

Structural equation modeling (SEM) is a versatile multivariate statistical technique and application of this method have been increasing since its introduction in the 1980s (Xiong et al. 2015). The main aim of this paper is to calculate its reliability and validity through an analysis based on SEM within a Confirmatory Factor Analysis (CFA). Based on Olmedo et al (2014), SEM provides some technical procedures and criteria for validation of measurement models under two conditions:

- Conditional independence, understood as a set of latent factors. For instance, skills, attitudes or perceptions, that influences a group of observed variables measured by the questions that make up a scale. The answers are mutually independent, but conditioned by the latent variable which determines them.

- Latent factors can be quantified by a dimensional structure based on a Substantive Theory that postulates the existence of psychological constructs that perform a causal influence on people's responses to a reactive group. 
In theory, SEM models are also incorporated with two sub-models such as the measurement model and the structural model. The so-called measurement model is based on the concept of using factor analysis to describe the latent variables and measured by the observed variables. The structural model is based on the concept of path analysis and determines the relationship between the different latent variables (Huang et al. 2013).

Based on this method questionnaire were prepared and focused interviews were conducted with technical experts involved in wastewater treatment and services in Malaysia. Based on these sessions, information such as wastewater systems, technological characteristics of these systems, current policies, customer services, and customers' expectations on wastewater treatment and service were listed. Technical experts also assisted in identifying the potential relative level of environmental and human harm associated with each wastewater system and the likely levels of other attributes. Such interviews had been instrumental to reveal service attributes that are important from the technical or supplier perspective.

\section{RESULTS AND DISCUSSION}

Descriptive statistics of the households' social, economic and demographic characteristics were reported in Table 1 below. The respondents interviewed were either heads of household or spouses of the heads of household, with a mean age of overall study area about 49 years. Malay respondents comprised the largest race composition of the survey, consistent with the distribution of this race within overall population. Most of the respondents had completed at least a secondary school education, with about a third of them having a university degree, implying a high literacy rate of the samples. Respondents were mostly private sector workers, with the majority of them working in management or professional occupation levels. The mean household income (overall study area) was MYR3500 for an average household of 5 persons with 55 percentage of respondent stayed at double story houses.

Table 1: Socio-Demographics of the Respondents

\begin{tabular}{cc}
\hline \hline Variable & Study Area \\
\hline Gender & Male $(85.6 \%)$ \\
Household head age & 47.8 \\
Race & Malay $(54.3 \%)$ \\
Household size & 5 \\
Educational level & Degree/ professional courses $(33.3 \%)$ \\
Household monthly income & MYR3500 (34.1\%) \\
Employment & Private sector $(46.1 \%)$ \\
Type of house & Double story house $(55.0 \%)$ \\
Ownership of residents & Owner (78.3\%) \\
\hline \hline
\end{tabular}




\subsection{Measurement Model}

Willingness to pay for improved wastewater treatment is measured by the following indicators: (i) environmental awareness (AWA1, AWA2 and AWA3), (ii) household attitude (ATT1, ATT2, ATT3 and ATT4) and (iii) perceptions of household in aspect of water use, wastewater treatment and services (PER1, PER2 and PER3). Each of the indicators of awareness, attitude and perceptions is measured by 5-point measurement scale ranging from "strongly disagree" to "strongly agree".

The Confirmatory Factor Analysis (CFA) aims to improve the questionnaire through structural model configuration, based on a criterion of maximum likelihood according to the multivariate normality criteria of items (Moreno et al. 2014). Confirmatory Factor Analysis (CFA) was applied based on Explanatory Factor Analysis (EFA) by an extraction method of calculating the Kaiser-Meyer-Olkin index and Cronbach's Alpha. Various measures exist to assess the goodness-of-fit of a SEM: $\chi^{2}$, goodness of fit index (GFI), adjusted goodness of fit index (AGFI), comparative fit index (CFI), normed fit index (NFI) and the root mean square error of approximation (RMSEA). However, there are no widely accepted cut-offs for these goodness-of-fit indices (Tang et al., 2013). The $\chi^{2}$ reflects the distance between the sample covariance matrix and the theoretical covariance matrix based on the hypothesized model. In this case, the higher the p-value of the $\chi^{2}$, the better the overall goodness-of-fit. Final standardized factor loadings for the measurement model are shown in Table 2.

Table 2: Fit Measures for Measurement Model

\begin{tabular}{ccc}
\hline \hline Consistency Measure & Value & Consistency \\
\hline RMSEA & 0.041 & Good Consistency \\
GFI & 0.978 & Good Consistency \\
AGFI & 0.962 & Good Consistency \\
CFI & 0.988 & Good Consistency \\
TLI & 0.983 & Good Consistency \\
NFI & 0.976 & Good Consistency \\
$\chi^{2} / \mathrm{df}$ & 2.013 & Good Consistency \\
\hline \hline
\end{tabular}

The measurement model included three latent constructs such as awareness, attitudes and perception measured by 10 items (Figure 1). Correlations among indicators across constructs ranged from 0.39 to 0.59 , with the greatest number of correlations occurring between attitudes and perception $(n=600)$. The overall fit of the measurement model was acceptable based on fit indices $\left(\chi^{2}=2.013\right.$, RMSEA $=0.041, \quad \mathrm{GFI}=0.978$, AGFI=0.962, CFI=0.988), TLI=0.983 and NFI=0.976).

Furthermore, the findings of Cronbach Alpha reliability index of three constructs (awareness, attitudes and perception) are summarized in Table 3. Cronbach Alpha value shows good consistency and acceptable based on the cut-off value $(\geq 0.7)$. 
Figure 1: Measurement Model

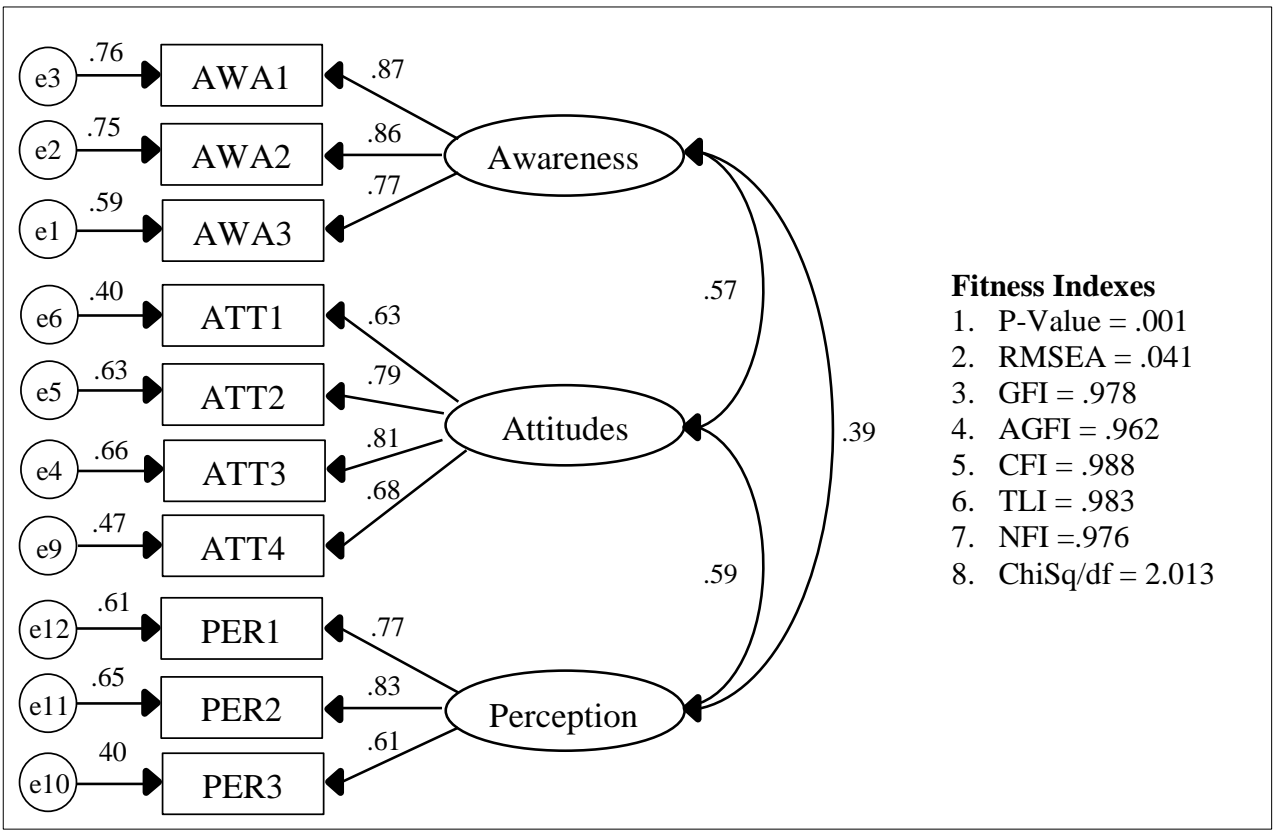

Table 3: Reliability of Measurement Instruments

\begin{tabular}{ccc}
\hline \hline Construct & $\begin{array}{c}\text { Cronbach Alfa } \\
\text { (cut-off value 0.7) }\end{array}$ & Consistency \\
\hline Awareness & 0.872 & Good Consistency \\
Attitudes & 0.813 & Good Consistency \\
Perception & 0.800 & Good Consistency \\
\hline \hline
\end{tabular}

Table 4: Skewness and Kurtosis Test

\begin{tabular}{ccccccc}
\hline \hline Variable & min & max & skew & c.r. & kurtosis & c.r. \\
\hline PER1 & 1.000 & 6.000 & $\mathbf{- . 7 3 2}$ & -7.321 & $\mathbf{. 4 9 3}$ & 2.467 \\
PER2 & 1.000 & 6.000 & $\mathbf{- . 3 5 2}$ & -3.524 & $\mathbf{. 1 7 5}$ & .876 \\
PER3 & 1.000 & 6.000 & $\mathbf{- . 4 7 1}$ & -4.709 & $\mathbf{- . 1 0 3}$ & -.515 \\
ATT1 & 1.000 & 6.000 & $\mathbf{- . 1 9 1}$ & -1.909 & $\mathbf{- . 1 3 0}$ & -.651 \\
ATT2 & 1.000 & 6.000 & $\mathbf{- . 0 7 0}$ & -.696 & $\mathbf{- . 1 3 5}$ & -.677 \\
ATT3 & 1.000 & 6.000 & $\mathbf{- . 2 1 3}$ & -2.131 & $\mathbf{- . 1 5 5}$ & -.777 \\
ATT4 & 1.000 & 6.000 & $\mathbf{- . 0 2 3}$ & -.233 & $\mathbf{- . 5 8 5}$ & -2.925 \\
AWA1 & 1.000 & 6.000 & $\mathbf{- . 3 5 3}$ & -3.533 & $\mathbf{- . 1 3 3}$ & -.664 \\
AWA2 & 1.000 & 6.000 & $\mathbf{- . 3 1 2}$ & -3.123 & $\mathbf{- . 4 2 9}$ & -2.144 \\
AWA3 & 1.000 & 6.000 & $\mathbf{- . 4 1 4}$ & -4.139 & $\mathbf{- . 1 7 2}$ & -.860 \\
\hline Multivariate & & & & & $\mathbf{4 5 . 0 3 6}$ & 35.604 \\
\hline \hline
\end{tabular}


Normality tests are used to determine whether a data set is modeled for normal distribution. This study used skewness and kurtosis to test for normality (Table 4). Skewness is a measure of the asymmetry of the probability distribution of a random variable about its mean. However, kurtosis is any measure of the "peakedness" of the probability distribution of a random variable (Zainuddin, 2012). Skewness value in the range of -1.0 to 1.0 shows data is normally distributed and multivariate kurtosis value lower than 50 acceptable model measurements.

\subsection{Structural Model}

The proposed structural model fit was acceptable $\left(\chi^{2}=4.458\right.$, RMSEA $=0.076$, GFI=0.942, AGFI=0.906, CFI=0.949), TLI=0.930 and NFI=0.936). The final model with significant pathways and standardized coefficients is shown in Figure 2, and standardized coefficients for indirect pathways are shown in Table 5. Households' awareness, attitudes and perception had a significant direct effect and positive relationship between willingness to pay for sewerage service improvement.

The model in this study provides a better approximation of the complexity of the actual relationship between willingness to pay for service improvement and household attitude-related constructs. Among the variables evaluated in this study, household's attitudes (87\%) had the strongest association with willingness to pay for sewerage service improvements.

Table 5: Fit Measures for SEM Model

\begin{tabular}{ccc}
\hline \hline Consistency Measure & Value & Consistency \\
\hline RMSEA & 0.076 & Good Consistency \\
GFI & 0.942 & Good Consistency \\
AGFI & 0.906 & Good Consistency \\
CFI & 0.949 & Good Consistency \\
TLI & 0.930 & Good Consistency \\
NFI & 0.936 & Good Consistency \\
$\chi^{2} / \mathrm{df}$ & 4.458 & Good Consistency \\
\hline \hline
\end{tabular}

Table 6 shows that all factor loadings in structural model are highly significant. In addition, the coefficients in structural model are substantially above the recommended minimum level of 0.20 (Tang et al., 2013). From Table 4 it follows that AWA1 and AWA2 are the most important indicators of Awareness while AWA3 is a weak indicator in structural model. Furthermore, ATT1, ATT2 and ATT3 the most important indicator for the variable Attitudes. For Perception, PER1 and PER2 are the most important indicators with satisfactory reliabilities while PER3 is the weakest indicator with very low reliability.

As hypothesized in the conceptual model, Awareness, Attitudes and Perception strongly interact indicating that household's Awareness, Attitudes and Perception of sewerage and wastewater treatment service in Malaysia is a prerequisite for growing aware and, vice versa, that awareness promotes and facilitates perception and attitudes. 
Figure 2: Structural Equation Model

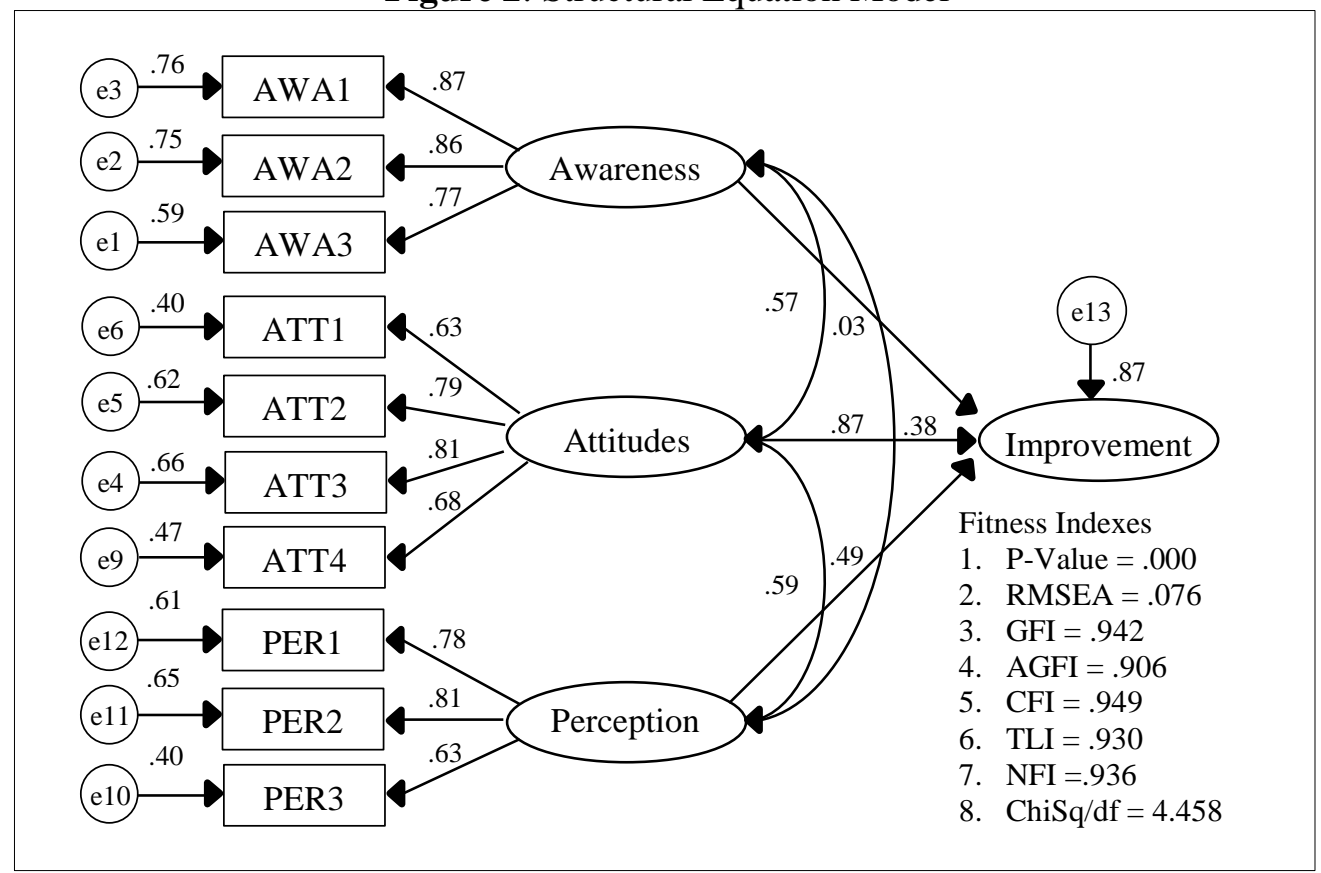

Table 6: Correlation and Maksimum Likelihood Estimates Regresion Weights (Standardizes Coefficients)

\begin{tabular}{ccccc}
\hline \hline \multicolumn{2}{c}{ Latent Variable Indicators } & Coefficient & S.E & c.r \\
\hline Awareness & AWA3 & 0.768 & & \\
& AWA2 & $0.865^{* * *}$ & 0.054 & 21.352 \\
& AWA1 & $0.872^{* * *}$ & 0.054 & 21.457 \\
\hline \multirow{2}{*}{ Attitudes } & ATT4 & 0.684 & & \\
& ATT3 & $0.812^{* * *}$ & 0.060 & 16.657 \\
& ATT2 & $0.790^{* * *}$ & 0.058 & 16.361 \\
& ATT1 & $0.631^{* * *}$ & 0.060 & 13.576 \\
\hline \multirow{2}{*}{ Perception } & PER3 & 0.633 & & 14.491 \\
& PER2 & $0.808^{* * *}$ & 0.076 & 14.327 \\
\hline \hline
\end{tabular}

Note: ${ }^{* * *} \mathrm{p}<0.01$

\section{CONCLUSION}

This paper analyzed the influence of household's characteristics and psychological factors on willingness to pay for sewerage and wastewater treatment service improvements based on a cross-sectional dataset of 600 households from Selangor, Malaysia. Structural equation modeling has been applied to estimate the conceptual model based on a brief 
on a brief literature review. Overall structural model shows Awareness, Attitude and Perception had positive correlation with willingness to pay for sewerage Service Improvements.

As awareness of the environmental issues and its impact on our life increases, more people are willing to change their behaviors and purchasing/consumption habits in order to help improve the environment. The demographical variables such as age, family income and family size were not having any positive significant relationship with consumer buying decision. This confirms that the consumer age, income and family size is not a criterion for making a buying decision of eco-friendly products. Consumer buying decision was having significant relationship with satisfaction, emotional value and green value of the consumers but it was not found significant relationship with product quality. This indicates that the awareness on green products (3\%) is not really impact on willingness to pay to improve quality of wastewater treatment. Water conservation attitudes and practice involves understanding the efficiency, opportunities

and impacts of certain water saving activities as well as the desire to continually reduce consumption (Willis et al. 2011). Results indicated that households with very positive environmental and water conservation attitudes consumed significantly less water in total and this construct mainly affect the willingness to pay for wastewater service improvement (87\%). The ability to use water is also highly dependent on the range of water using amenities available to a household, regardless of its size and socioeconomic profile. Again, there were some clear differences between the house categories for both water use inside as well as outside the home that help to explain the differences in attitude and behaviour towards water use revealed in the survey. Indah Water Konsortium (IWK) is Malaysia's national sewerage company which has been entrusted with the task of developing and maintaining a modern and efficient sewerage system for all Malaysians. Public perception about sewerage service provider positively correlated and affects willingness to pay for the sewerage service improvement (49\%).

Establishing reliable and sustainable water service infrastructure and facilities require substantial capital investments. There are still many thousands of kilometers of distribution piping and dozens of water treatment plants built in the 70's and 80's that are still in operations and need either rehabilitation or upgrade. In many areas where demands for drinking water have grown and new water treatment plants are required. Compounded by low tariffs and lack of funds, many water operators are still unable to effectively tackle pressing issues. In this case, very important to change public's perception on the water industry that will be beneficial to relevant the stakeholders namely government agencies, regulators, planners, utility providers, developers and other relevant parties in private sector, for the future development. Findings from this study will provide relevant policy inputs and the matching of consumer demand with the easibility of supply on the part of service providers. The major constraints to water and wastewater treatment faced by Malaysia are low sewerage tariff is unable to support the high operation and maintenance costs. In this case, changes in awareness, attitude and perception will help Malaysians to realize the responsibility and the importance of water and sewage management with regards to a safer environment. 


\section{ACKNOWLEDGEMENT}

Acknowledgement and appreciation to the Ministry of Education Malaysia for providing the research funds (LRGS/TD/2011/UTM-UKM/PT/04NT - Economics and Policy Imperatives for Sustainable Water and Wastewater Treatment) and also Rural Transformation project (AP-2014-017) that enables this study to be undertaken.

\section{REFERENCES}

Bayard, B., \& Jolly, C. (2007). Environmental Behavior Structure and Socio-Economic Conditions of Hillside Farmers: A Multiple-Group Structural Equation Modeling Approach. Ecological Economics, 62(3), 433-440.

Folmer, H. (2009). Why Sociology Is Better Conditioned to Explain Economic Behaviour Than Economics. Kyklos, 62(2), 258-274.

Huang, S. C., Lo, S. L., \& Lin, Y. C. (2013). Application of a Fuzzy Cognitive Map Based on a Structural Equation Model for the Identification of Limitations to the Development of Wind Power. Energy Policy, 63(December), 851-861.

Lo, C. W., \& Leow, C. S. (2014). Islamic Banking in Malaysia: A Sustainable Growth of the Consumer Market. International Journal of Trade, Economics and Finance, 5(6), 526.

Mamun, A., \& Zainuddin, Z. (2013). Sustainable river water quality management in Malaysia. IIUM Engineering Journal, 14(1), 29-42.

Moreno, E. M., Luna, E. B., Gomez, C. O., Lopez, J. E. (2014). Structural Equations Model (SEM) of a questionnaire on the evaluation of intercultural secondary education classrooms. Suma Psicologica, 21(1), 107-115.

Olmedo Moreno, E. M., De Luna, E. B., Olmos Gomez, M. D. C., \& Lopez, J. E. (2014). Structural Equations Model (Sem) of a Questionnaire on the Evaluation of Intercultural Secondary Education Classrooms. Suma Psicologica, 21(2), 107-115.

Tang, J., Folmer, H., \& Xue, J. (2013). Estimation of Awareness and Perception of Water Scarcity among Farmers in the Guanzhong Plain, China, by Means of a Structural Equation Model. Journal of Environmental Management, 126, 55-62.

Weck-Hannemann, H., \& Frey, B. S. (1995). Are Incentive Instruments as Good as Economists Believe? Some New Considerations. In B. Lans \& C. Sijbren (eds.) Public Economics and the Environment in an Imperfect World. Boston: Kluwer Publishers.

Willis, R. M., Stewart, R. A., Panuwatwanich, K., Williams, P. R., \& Hollingsworth, A. L. (2011). Quantifying the Influence of Environmental and Water Conservation Attitudes on Household End Use Water Consumption. Journal of Environmental Management, 92(8), 1996-2009.

Xiong, B., Skitmore, M., \& Xia, B. (2015). A Critical Review of Structural Equation Modeling Applications in Construction Research. Automation in Construction, 49(Part A), 59-70.

Zainudin, A. (2012). A Handbook on SEM Structural Equation Modeling (Edition 6). Kota Bharu: Universiti Teknologi Mara Kelantan. 